\title{
Campylobacter coli infection in pet birds in southern Italy
}

\author{
Ludovico Dipineto *, Luca Borrelli, Antonino Pace, Violante Romano, Stefano D'Orazio, Lorena Varriale, \\ Tamara Pasqualina Russo and Alessandro Fioretti
}

\begin{abstract}
Avian species are considered as the main reservoir of Campylobacter spp. However, few data are available on the presence of this microorganism in pet birds. This study was therefore performed to determine the prevalence of Campylobacter spp. in pet birds bred in southern Italy. Faecal samples were collected from 88 cages housing different species of pet birds and examined by bacteriological culture and polymerase chain reaction. A total of $13.6 \%$ of the cage samples were positive for Campylobacter coli. Other Campylobacter spp. were not found. The study shows that $C$. coli can be isolated from the cages of apparently healthy pet birds, which should therefore be considered as potential carriers of $C$. coli and a possible source of infection for humans and companion animals.
\end{abstract}

Keywords: Campylobacter spp., Campylobacter coli, Avian species, Pet birds, Zoonosis

\section{Findings}

Thermotolerant Campylobacter spp., mainly Campylobacter jejuni and Campylobacter coli, are the most commonly reported bacteria in enteric infections in humans. The incidence of human campylobacteriosis has increased in both developed and developing countries over the last 10 years [1]. These bacterial species colonize the intestinal mucosa of most warm-blooded animals, including food-producing animal species and humans [2].

Several avian species are considered the main reservoirs of Campylobacter spp. [3, 4]. Nevertheless, current scientific knowledge on the presence of Campylobacter spp. in pet birds is scarce. To address this lack of information, the present study was undertaken to assess the presence of Campylobacter spp. in pet birds bred in southern Italy.

The study was carried out from July to December 2015 in 14 privately owned bird farms located in the Campania region, southern Italy. Sampling was conducted with the approval of the owners. In each farm, the bird population ranged from 20 to 100 birds. Pooled faecal samples were

*Correspondence: ludovico.dipineto@unina.it Department of Veterinary Medicine and Animal Productions, Università di Napoli Federico II, Via della Veterinaria 1, 80137 Naples, Italy obtained from the floor of 88 cages with birds belonging to the families of Estrildidae (33 cages with 118 birds), Fringillidae ( 28 cages with 64 birds) and Psittacidae (27 cages with 43 birds) (Table 1). The cage was used as an epidemiological unit, and each cage housed from one to five birds. All birds were apparently in healthy condition and none received any antimicrobial treatment during the study period.

Before the collection of faecal samples, a sheet of sterile aluminum foil was placed under the grid of each cage overnight. Faecal samples were then collected by sterile cotton tipped swabs. Each sample swab was stored in Amies Charcoal Transport Medium (Oxoid, Basingstoke, UK) at $4{ }^{\circ} \mathrm{C}$, transported to the laboratory, and analyzed within $2 \mathrm{~h}$ of collection. Samples were inoculated into Bolton selective enrichment broth (Oxoid) and incubated at $42{ }^{\circ} \mathrm{C}$ for $48 \mathrm{~h}$ under microaerobic conditions provided by CampyGen (Oxoid). Subsequently, each sample was streaked onto Campylobacter blood-free selective agar (modified charcoal cefoperazone deoxycholate agar; Oxoid) with the corresponding supplement (SE 155; Oxoid). The plates were examined for typical Campylobacter colonies after additional incubation at $42{ }^{\circ} \mathrm{C}$ for $48 \mathrm{~h}$ under microaerobic conditions. The suspected colonies were purified on sheep blood agar (Oxoid) and finally incubated for $24 \mathrm{~h}$ at $42{ }^{\circ} \mathrm{C}$. Colonies comprising 
Table 1 Family and species of birds examined, related bird populations and number of cages tested with percentage of cages being positive for Campylobacter coli

\begin{tabular}{llll}
\hline Family & Birds tested & $\begin{array}{l}\text { Bird population/number } \\
\text { of cages tested }\end{array}$ & $\begin{array}{l}\text { Number of positive/pooled } \\
\text { fecal samples tested (\%) }\end{array}$ \\
\hline Estrildidae & Erythrura gouldiae & $67 / 22$ & $0 / 22(0 \%)$ \\
& Lonchura striata domestica & $16 / 4$ & $0 / 4(0 \%)$ \\
Fringillidae & Taeniopygia guttata & $35 / 7$ & $7 / 7(100 \%)$ \\
& Carduelis carduelis & $18 / 9$ & $0 / 9(0 \%)$ \\
Psittacidae & Serinus canaria & $46 / 19$ & $0 / 19(0 \%)$ \\
& Agapornis spp. & $20 / 10$ & $2 / 10(20 \%)$ \\
& Amazona spp. & $6 / 6$ & $3 / 6(50 \%)$ \\
& Arinae subfamily & $6 / 3$ & $0 / 3(0 \%)$ \\
& Cacatuidae family & $2 / 2$ & $0 / 2(0 \%)$ \\
Loriinae subfamily & $2 / 1$ & $0 / 1(0 \%)$ \\
& Melopsittacus undulatus & $2 / 1$ & $0 / 1(0 \%)$ \\
& Nymphicus hollandicus & $2 / 1$ & $0 / 1(0 \%)$ \\
& Psittacus erithacus & $3 / 3$ & $0 / 3(0 \%)$ \\
\hline
\end{tabular}

Bird population refers to the total number of birds housed in the total number of cages examined

curved or spiral motile rods were examined by phase contrast microscopy, presumptively identified as Campylobacter spp. and submitted to a multiplex polymerase chain reaction $(\mathrm{PCR})$ analysis following the procedures described by Gargiulo et al. [5].

All positive isolates were tested for the antimicrobial susceptibility by using the disk diffusion method and breakpoints as suggested by Sifré et al. [6]. Because few breakpoints are available for Campylobacter spp., only ciprofloxacin $(5 \mu \mathrm{g})$, erythromycin $(15 \mu \mathrm{g})$, and tetracycline $(30 \mu \mathrm{g})$ were tested.

Twelve out of the 88 cages [13.6\%; 95\% confidence interval (CI) 7.6-23.0\%] were positive for a Campylobacter spp., which in all cases was identified as $C$. coli. Seven out of 33 cages with bids of the Estrildidae family (21.2\%; 95\% CI 9.6-39.4\%) and five out of 27 cages with birds of the Psittacidae family (18.5\%; 95\% CI 7.0-38.8\%) were infected with $C$. coli, while all cages $(\mathrm{n}=28)$ with birds of the Fringillidae family were negative (Table 1 ). Out of the 14 farms, five farms had infected birds (35.7\%; 95\% CI 14.0-64.4\%). All C. coli isolates were sensitive to erythromycin and resistant to tetracycline and ciprofloxacin.

Except for a study reporting a prevalence of campylobacteriosis in pet birds in Argentina to 19.0\% [7], data on the occurrence of campylobacteriosis in pet birds are scarce. In our study, $13.6 \%$ of the cage samples were found positive for $C$. coli. The majority of the positive samples (7/12) originated from Taeniopygia guttata species in which $C$. coli was found in all samples (7/7 species samples) followed by Amazona spp. (3/12 positive samples; 3/6 species samples) and Agapornis spp. (2/12 positive samples; $2 / 10$ species samples).

This study shows that $C$. coli may be excreted in the faeces of apparently healthy pet birds. Pet birds may be a potential source of $C$. coli transmission to humans and the risk of transmission of antimicrobial resistant bacteria between pet birds and other animal species and humans should be considered. The adoption of good hygiene practices when handling pet birds should be promoted.

\section{Authors' contributions}

LD and LB planned the study. LB, VR, SD and AP collected the samples. AP, TPR and $L V$ performed the laboratory analyses. $L D$ and $A F$ obtained the funding and coordinated the study. LD, VR and SD drafted the manuscript. All authors read and approved the final manuscript.

\section{Acknowledgements}

The authors would like to thank the Campania region, which financially supported this project (Legge 5/2002 ann.tà 2007, CUP E62115000330002).

\section{Competing interests}

The authors declare that they have no competing interests.

Received: 30 July 2016 Accepted: 20 December 2016

Published online: 06 January 2017

References

1. Kaakoush NO, Castaño-Rodríguez N, Mitchell HM, Man SM. Global epidemiology of Campylobacter infection. Clin Microbiol Rev. 2015;28:687-720.

2. Newell DG, Fearnley C. Sources of Campylobacter colonization in broiler chickens. Appl Environ Microbiol. 2003;69:4343-51.

3. Dipineto L, Gargiulo A, De Luca Bossa LM, Rinaldi L, Borrelli L, Menna $L F$, Fioretti A. Prevalence of thermotolerant Campylobacter in pheasants (Phasianus colchicus). Avian Pathol. 2008;37:507-8. 
4. Dipineto L, Gargiulo A, De Luca Bossa LM, Rinaldi L, Borrelli L, Santaniello $A$, et al. Prevalence of thermotolerant Campylobacter in partridges (Perdix perdix). Lett Appl Microbiol. 2009;49:351-3.

5. Gargiulo A, Sensale M, Marzocco L, Fioretti A, Menna LF, Dipineto L. Campylobacter jejuni, Campylobacter coli, and cytolethal distending toxin (CDT) genes in common teals (Anas crecca). Vet Microbiol. 2011;150:401-4
6. Sifré E, Salha BA, Ducournau A, Floch P, Chardon H, Mégraud F, Lehours P. EUCAST recommendations for antimicrobial susceptibility testing applied to the three main Campylobacter species isolated in humans. J Microbiol Methods. 2015;119:206-13.

7. López CM, Giacoboni G, Agostini A, Cornero FJ, Tellechea DM, Trinidad JJ. Thermotolerant Campylobacters in domestic animals in a defined population in Buenos Aires, Argentina. Prev Vet Med. 2002;55:193-200.

\section{Submit your next manuscript to BioMed Central and we will help you at every step:}

- We accept pre-submission inquiries

- Our selector tool helps you to find the most relevant journal

- We provide round the clock customer support

- Convenient online submission

- Thorough peer review

- Inclusion in PubMed and all major indexing services

- Maximum visibility for your research

Submit your manuscript at www.biomedcentral.com/submit 